\title{
Estimation of Nocturnal Cooling Temperature on a Regional Scale
}

\author{
K. Yamada, R.Shirooka and T.Hirota \\ Hokkaido National Agricultural Experiment Station \\ Hitsujigaoka,Toyohiraku,Sapporo 062,Japan
}

\begin{abstract}
The feasibility of regional estimation of nocturnal cooling between the evening mean temperatures and the next morning's minimum temperatures was estimated using with a nocturnal cooling model. Here, we used the data of the Automated Meteorological Data Acquisition System (AMeDAS) and the aerological observation at Sapporo. In the present analysis, we suppose that the possible temperature drop by nocturnal cooling on each clear night are a constant across a region of about $100 \mathrm{~km} \times 150 \mathrm{~km}$. The possible temperature drops in the 32 cases were about from 15 degree to 24 degree. The ratio of the actual temperature drops at the AMeDAS monitoring points to the possible temperature drop were from about 0.5 to 0.6 at the higher elevations of the inland areas, 0.4 to 0.5 in the plains and around 0.3 in the coastal areas. There was an interesting similarity between the values and the geographical and topographical futures. A model using these values as parameters was applied for 11-clear days in 1990. Estimated values were found to be less than the observed values, but their errors were within almost 2 degrees.
\end{abstract}

Key words: Nocturnal cooling, Minimum temperature, AMeDAS,

\section{Introduction}

Some analyses of the relationship among the climatic value, yearly or monthly mean temperature, and topographical features in Japan have been carried out in order to estimate the spatial distribution of temperature over square kilometers unit of an agriculture and forestry region. Seino (1993) reported that the accuracy of spatial estimation of air temperatures could be very poor for short term, for example daily minimum temperature and daily maximum. Yamada (1995) showed that the spatial distribution of air temperature in the evening was linearly related to the elevation above sea level with little influence from the weather and wind speed. While, the spatial distribution of minimum air temperature in the morning and nocturnal cooling were much influenced by the above factors. $\mathrm{He}$ also showed that the spatial distribution of a short term air temperature near the surface could be estimated with aerological and surface meteorological data in central Japan.

The objective of this paper is to reveal the feasibility of spatial estimation of air temperature in the middle west of Hokkaido using a nocturnal cooling model. The first point is to estimate the nocturnal cooling

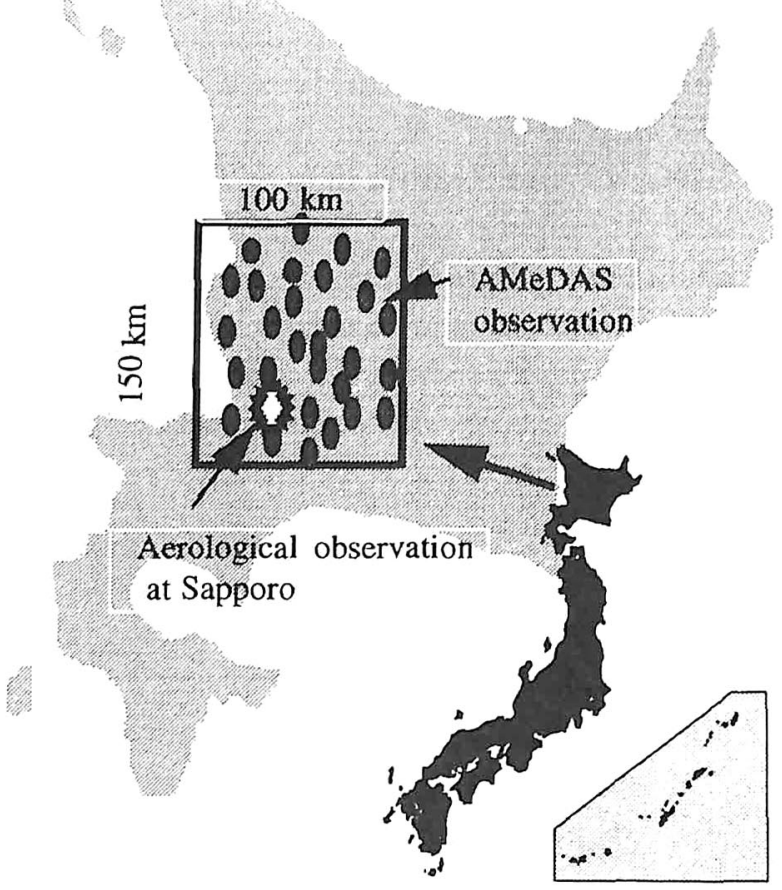

Fig.1 Data map in the middle west of Hokkaido 
temperature using Kondo's model (1981). The second point is to investigate the applicability of the model for clear days, with a cloud level of under 3, from May to August in 1990.

\section{Materials and Methods}

\subsection{Nocturnal cooling model}

The nocturnal cooling model is given (Kondo, 1981) as

$$
\Delta \mathrm{T}_{\mathrm{s}} / \Delta \mathrm{T}_{\mathrm{s}, 0}=\alpha\{1-\exp (-\beta / \mathrm{U})\}
$$

where $\Delta \mathrm{Ts}\left({ }^{\circ} \mathrm{C}\right)$ is the actual temperature drop which is subtracted the next morning minimum temperatures from the evening mean temperatures. The AMeDAS in the middle west of Hokkaido shown in Fig. 1 were applied. $\Delta \mathrm{Ts}, 0\left({ }^{\circ} \mathrm{C}\right)$ is the possible temperature drop by nocturnal cooling on a calm night, without the effects of sensible heat and latent heat. $U(\mathrm{~m} / \mathrm{s})$ is the wind speed at a height of $1,500 \mathrm{~m}$ at 20:30 LST at Sapporo.

$\Delta \mathrm{T}_{\mathrm{s}, 0}$ is evaluated by the equation

$$
\left.\Delta \mathrm{T}_{\mathrm{s}, 0} \equiv \mathrm{T} 0-\mathrm{Te} \fallingdotseq(\mathrm{T} 0 / 4)\left\{1-\mathrm{L} 0 / \sigma \mathrm{T} 0^{4}\right)\right\}
$$

where T0 $\left({ }^{\circ} \mathrm{C}\right)$ is the mean of evening temperatures at $1.5 \mathrm{~m}$ and around $150 \mathrm{~m}$ above the ground, $\mathrm{Te}\left({ }^{\circ} \mathrm{C}\right)$ is the virtual minimum temperature which is calculated using the equation of $\sigma \mathrm{Te}^{4}-\mathrm{L} 0=0$ as the thermal conductivity in the soil becomes zero. The downward longwave radiation LO $\left(\mathrm{w} / \mathrm{m}^{2}\right)$ is evaluated by an empirical formulation (Kondo et al.,1990) with precipitation calculated from the aerological observation data taken at 20:30 LST in Sapporo. $\sigma$ is the Stefan-Boltzmann constant.

\section{Results and Disccusion}

3.1 The downward longwave radiation and the possible temperature drop

Table 1 shows examples of the downward longwave radiation (L0) at 20:30 LST, the virtual minimum temperature (Te) when sensible heat and latent heat are zero, and the evening mean temperatures (T0) from 18 to 20 LST at one hour intervals with aerological observation data at Sapporo. The possible temperature drop $(\Delta \mathrm{Ts}, 0)$ each night is obtained by subtracting Te from $\mathrm{T} 0$.

The ranges of $\mathrm{LO}$, in summer, are about from 295 to $335 \mathrm{w} / \mathrm{m}^{2}$ and $\Delta \mathrm{Ts}, 0$ are from about 15 to $24\left({ }^{\circ} \mathrm{C}\right)$. In the present analysis, we suppose that $\mathrm{L} 0$ and $\Delta \mathrm{Ts}, 0$ on each night are a constant and are the same over all AMeDAS monitoring points in Fig. 1.

\subsection{Parameter $\alpha$ and $\beta$}

The mean values of parameters $\alpha$ and $\beta$ were evaluated for considerably clear

\begin{tabular}{|c|c|c|c|c|c|c|}
\hline Year & Month & Day & LO & $\mathrm{Te}\left({ }^{\circ} \mathrm{C}\right)$ & T0 $\left({ }^{\circ} \mathrm{C}\right)$ & $\Delta \mathrm{Ts}, \mathrm{O}\left({ }^{\circ} \mathrm{C}\right)$ \\
\hline 91 & 5 & 30 & 294 & -4.88 & 14.4 & $\overline{19.3}$ \\
\hline 91 & 6 & 21 & 325 & 2.05 & 20.4 & 18. 4 \\
\hline 91 & 8 & 22 & 344 & 5.92 & 21.7 & 15.8 \\
\hline 91 & 8 & 23 & 317 & 0.26 & 21.4 & 21. 1 \\
\hline 91 & 8 & 24 & 332 & 3.49 & 23.3 & 19.8 \\
\hline 91 & 8 & 25 & 329 & 2.78 & 21.4 & 18. 6 \\
\hline 91 & 8 & 26 & 315 & -0.07 & 17.8 & 17. 9 \\
\hline 91 & 8 & 27 & 315 & -0.22 & 19.1 & 19. 3 \\
\hline 91 & 8 & 28 & 320 & 0.95 & 21.6 & 20.6 \\
\hline 91 & 9 & 7 & 309 & -1.49 & 20.8 & 22. 3 \\
\hline 92 & 6 & 26 & 316 & 0.17 & 18.9 & 18. 7 \\
\hline 92 & 6 & 27 & 319 & 0.71 & 22.5 & 21.8 \\
\hline 92 & 6 & 28 & 327 & 2.46 & 22.6 & 20.1 \\
\hline 92 & 6 & 29 & 323 & 1.48 & 23.1 & 21.6 \\
\hline 92 & 7 & 6 & 331 & 3.24 & 24 & 20.8 \\
\hline 92 & 7 & 16 & 333 & 3.58 & 20.5 & 16. 9 \\
\hline 92 & 8 & 4 & 306 & -2.08 & 18 & 20.1 \\
\hline 92 & 8 & 26 & 323 & 1.59 & 24.3 & 22.7 \\
\hline 92 & 9 & 13 & 312 & -0.87 & 20.6 & 21.5 \\
\hline 93 & 7 & 1 & 315 & -0.24 & 17.7 & 17. 9 \\
\hline 93 & 7 & 2 & 320 & 0.93 & 20.9 & 20.0 \\
\hline 93 & 7 & 3 & 313 & -0.58 & 19 & 19. 6 \\
\hline 93 & 7 & 4 & 319 & 0.82 & 21.5 & 20.7 \\
\hline 93 & 7 & 5 & 309 & -1.37 & 21.1 & 22.5 \\
\hline 93 & 7 & 6 & 316 & 0.10 & 21.6 & 21.5 \\
\hline 93 & 7 & 7 & 310 & -1.19 & 21 & 22.2 \\
\hline 93 & 7 & 8 & 302 & -2.94 & 20.3 & 23.2 \\
\hline 93 & 8 & 4 & 318 & 0.48 & 20.8 & 20.3 \\
\hline 93 & 8 & 5 & 335 & 4.11 & 19.3 & 15. 2 \\
\hline 93 & 8 & 6 & 306 & -2.17 & 19.3 & 21.5 \\
\hline 93 & 8 & 7 & 297 & -4.10 & 17.4 & 21.5 \\
\hline 93 & 9 & 1 & 295 & -4.56 & 19.6 & 24. 2 \\
\hline
\end{tabular}
weather conditions that the mean cloud 

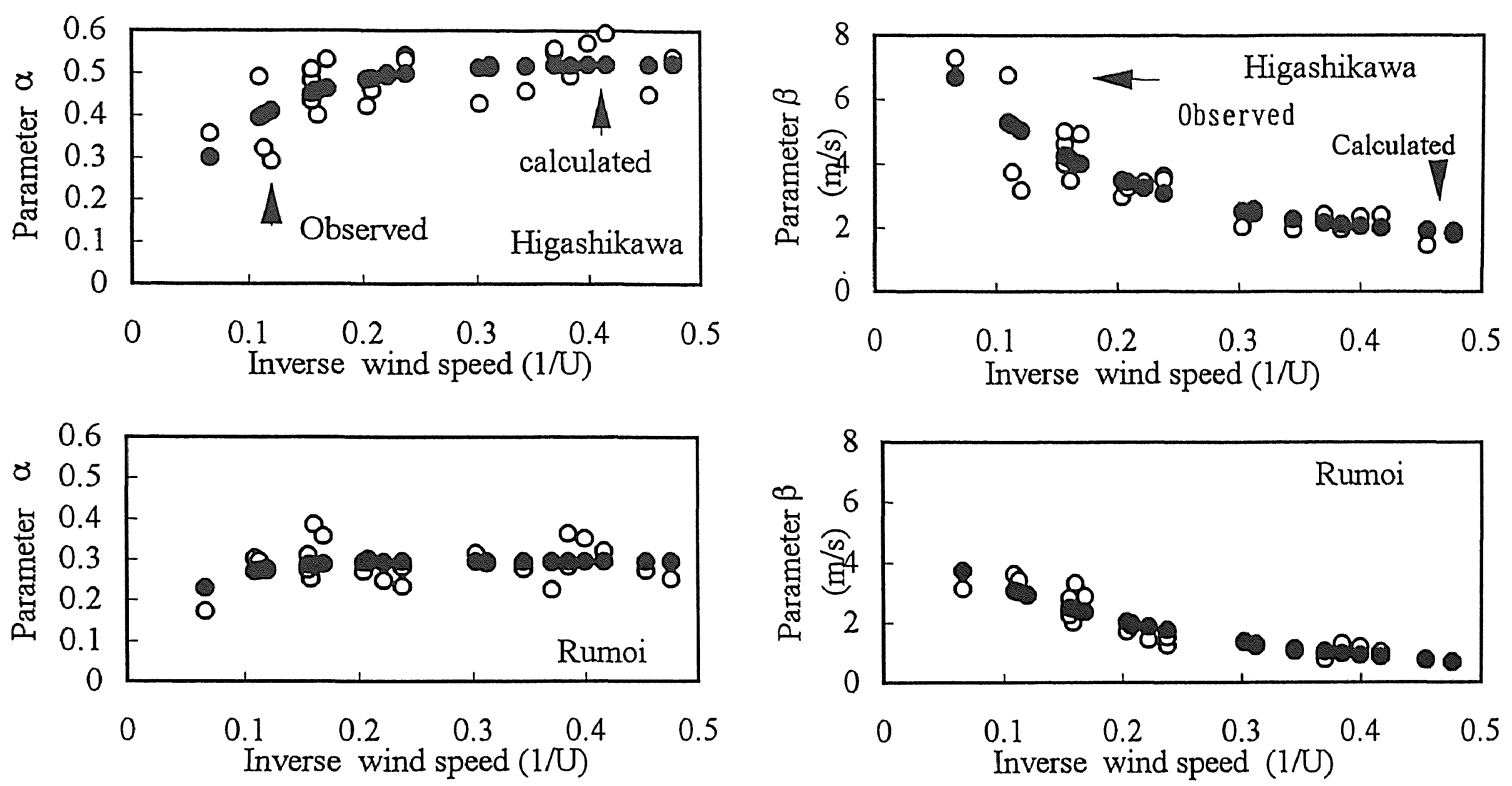

Fig. 2. Example of values of Parameter $\alpha$ on Table 1 Fig. 3. Example of values of Parameter $\beta$ on Table 1.

in Table 1, in the summer seasons from 1991 to 1993. The mean value of $\alpha$ of each AMeDAS observation point was determined for a calm $U=1 \mathrm{~m} / \mathrm{s}$ from an approximate equation between the nocturnal cooling rate and the reciprocal of the wind speed at the height of $1,500 \mathrm{~m}$ for each night (Fig.2). The mean value of $\beta$, using the same method, was decided for a strong wind of $U=20 \mathrm{~m} / \mathrm{s}$ by substituting values of $\alpha$ and wind speed for each night into equation (1) (Fig.3).

Table 2 shows parameters $\alpha, \beta$ and the elevation of each AMeDAS observation point.

The values of $\alpha$ were from about 0.5 to 0.6 at the higher elevations of the inland areas, 0.4 to 0.5 in the plains and around 0.3 in the coastal areas.

Parameter $\alpha$ is related to the thermal characteristics near the surface, the advection effect and the accumulation of cold air at the observation site. It is shown that there is an interesting similarity between the value of $\alpha$ and the topographical locations. The tendencies between the values of $\alpha$ and the topographical locations are similar to the results of Kondo and Mori (1982) and Yamada (1995). But, the values in the plains are smaller by about $20 \%$ than those of Kondo and Mori (1982).
Table 2 Values of parameter $\alpha$ and $\beta$ in the middle west of Hokkaido.

\begin{tabular}{|c|c|c|c|}
\hline \multirow[t]{2}{*}{ Observation } & \multicolumn{2}{|c|}{ Parameters } & \multirow{2}{*}{$\begin{array}{c}\text { Elevation } \\
\mathrm{m}\end{array}$} \\
\hline & $\alpha$ & $\beta$ & \\
\hline \multicolumn{4}{|c|}{ Observations in the inland area } \\
\hline Etanbetsu & 0.628 & 10.1 & 140 \\
\hline Hippu & 0.571 & 10.1 & 167 \\
\hline Kamikawa & 0.561 & 5.1 & 350 \\
\hline Asahikawa & 0.529 & 6.5 & 112 \\
\hline Higashikawa & 0.521 & 7.3 & 215 \\
\hline Biei & 0.584 & 7 & 250 \\
\hline Kamifurano & 0.575 & 6.3 & 220 \\
\hline Sorachiyoshino & 0.543 & 5.7 & 100 \\
\hline Furano & 0.539 & 6.9 & 174 \\
\hline Ashibetu & 0.53 & 10.3 & 90 \\
\hline Rokugou & 0.608 & 5.8 & 315 \\
\hline Ikutora & 0.617 & 6.7 & 361 \\
\hline Urukappu & 0.486 & 8.3 & 332 \\
\hline \multicolumn{4}{|c|}{ Observations in the plain } \\
\hline Horonuka & 0.415 & 8.1 & 20 \\
\hline Ishikarinumata & 0.464 & 9.6 & 63 \\
\hline Fukagawa & 0.445 & 10.6 & 55 \\
\hline Takikawa & 0.456 & 7.9 & 48 \\
\hline Tsukigata & 0.403 & 5.7 & 50 \\
\hline Bibai & 0.416 & 5.9 & 25 \\
\hline Iwamizawa & 0.412 & 6.5 & 42 \\
\hline Nishinopporo & 0.327 & 4.9 & 22 \\
\hline Eniwashimamasu & 0.358 & 3.2 & 30 \\
\hline Naganuma & 0.32 & 6.2 & 13 \\
\hline \multicolumn{4}{|c|}{ Observations in the coastal area } \\
\hline Rumoi & 0.294 & 4.1 & 24 \\
\hline Mashike & 0.285 & 4.4 & 36 \\
\hline Hamamasu & 0.318 & 8.7 & 3 \\
\hline Atsuta & 0.339 & 8.5 & 5 \\
\hline Shinshinotsu & 0.35 & 4.4 & 9 \\
\hline Yamaguchi & 0.344 & 3.7 & 5 \\
\hline Ishikari & 0.287 & 5.9 & 5 \\
\hline
\end{tabular}


The values of $\beta$ were from about $3 \mathrm{~m} / \mathrm{s}$ to $10 \mathrm{~m} / \mathrm{s}$. Parameter $\beta(\mathrm{m} / \mathrm{s})$ is related to roughness for wind speed in the region of about $10 \mathrm{~km}$ or more at each observation site (Kondo, 1981). It is not apparent that there is an interesting relationship between the values of $\beta$ and the topographical locations. It seems that more analysis using detailed topographical features from the observation sites is necessary.

\subsection{Probable estimation of the model}

The model using the above values in the plains and coastal areas, across a region of about $80 \mathrm{~km} \times 100 \mathrm{~km}$, were estimated for 11-clear days from May to August of 1990 (see Fig.3). The mean cloud amounts in the day and the day before shown in the Table 3 were less than 2.5 .

The correlation coefficients between the estimated values and the observed values on each day is shown in Table3. Their coefficients are comparatively high except for a few days. The results for all the days are shown in Fig.4. The estimated values were lower than the actual values as nocturnal cooling increase.

Table 3 Correlation Between observed and calculated values.

\begin{tabular}{c|rr}
\hline month/day & Correlation & \multicolumn{1}{l}{ St.dev. } \\
$5 / 25$ & 0.686 & 0.733 \\
$5 / 26$ & 0.766 & 0.735 \\
$6 / 5$ & 0.710 & 0.766 \\
$6 / 29$ & 0.507 & 1.038 \\
$6 / 30$ & 0.916 & 0.660 \\
$7 / 1$ & 0.884 & 0.638 \\
$7 / 2$ & 0.838 & 0.660 \\
$7 / 11$ & 0.655 & 0.749 \\
$7 / 27$ & 0.730 & 0.768 \\
$8 / 3$ & 0.752 & 0.790 \\
\hline Total & 0.612 & 1.285 \\
\hline
\end{tabular}

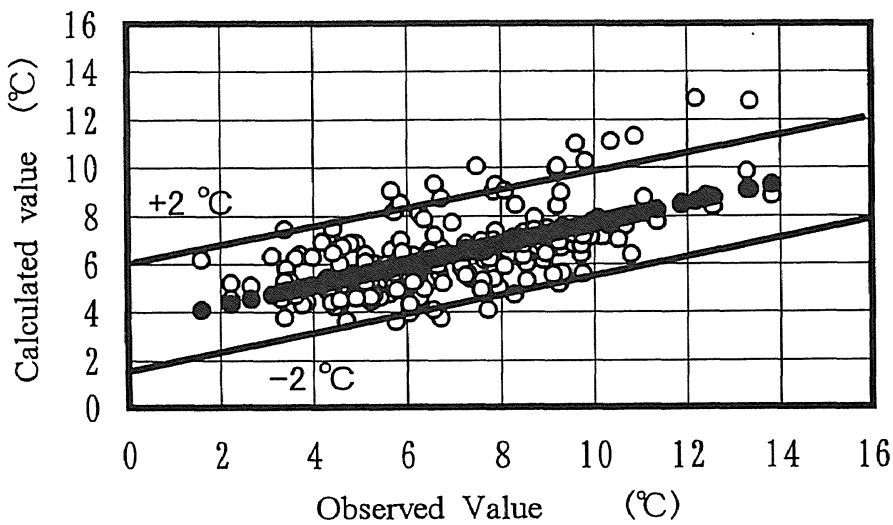

Fig.4 Comparison Between observed and calculated values (total).

The region we used in summer has two predominant wind directions which were a westerly wind from the Japan Ocean and an easterly from the Pacific Ocean. The air temperature of the westerly is not so low, but the easterly is sometimes low. The analysis of its influence is the subject of a future study.

\section{Reference}

Kondo, J., and Y: mori, 1982: Analysis on nocturnal cooling at the regional meteorological observations. Tenki. 29, 255-267.

Kondo, J. 1982: Preliminary theoretical study on nocturnal cooling over complex terrain. Tenki. 29, 935-949.

Seino, H., 1993: An estimation of distribution of meteorological elements using GIS and AMeDAS data. J. Agr. Met. 48,379-383.

Yamada, K., 1995: Short-term air temperature on a regional scale and its estimation with a nocturnal cooling model. J. Agr. Met. 51(4), 345-354. 